\title{
REPRODUCTION OF FEMALE DWARF MICE TREATED WITH PROLACTIN
}

\author{
ANDRZEJ BARTKE* \\ The Institute for Cancer Research, Philadelphia 11, Pennsylvania \\ (Received 11th Fune 1965, revised 10th Fuly 1965)
}

\begin{abstract}
Summary. Genetically dwarf female mice are sterile but reproduction and lactation can be induced with prolactin-producing heterotopic pituitary homografts. To test if prolactin deficiency is the sole cause of the sterility, female dwarf mice were treated with purified prolactin.

Dwarf (dwdw) and Ames dwarf (dfdf) mice in which the vaginae opened spontaneously were mated to non-dwarf males and injected with sheep prolactin starting on the day of plug formation. Pregnancy, delivery and lactation were obtained in both kinds of dwarf mouse indicating that, in the stocks used, the addition of prolactin alone is sufficient for reproduction.
\end{abstract}

\section{INTRODUCTION}

Female mice homozygous for hereditary dwarfism (dwarf, dw, and Ames dwarf, df) may ovulate and mate but do not become pregnant. Grafting pituitaries of non-dwarf mice into the renal capsule of dwarf females resulted in fertility of both Snell and Ames dwarfs. Females bearing grafts often produced several litters and lactated sufficiently to raise the majority of their young to weaning (Bartke, 1965b). Recently it was demonstrated that pituitaries of dwarf mice do not produce significant amounts of luteotrophin when grafted into the renal capsule of normal intact female mice (Bartke, 1965a). It was concluded that luteotrophin (prolactin) deficiency may be responsible for the sterility (Bartke, 1965b). In the present work, purified prolactin was administered to female dwarf mice to test if prolactin deficiency is solely responsible for their sterility and to compare the results of such treatment with the results of pituitary homografts.

\section{MATERIALS AND METHODS}

All dwarf mice used were from the non-inbred stocks used in previous work with pituitary homografts (Bartke, 1965b). The animals were kept in an air-conditioned room with artificial illumination from 07.00 hours until 19.00 hours with the temperature maintained at $24.5^{\circ} \mathrm{C}$, and were fed Old Guilford Bar Harbor Diet and tap water ad libitum.

Twenty-one Snell dwarf females and twenty-nine Ames dwarf females, 3 to

* Exchange student at the University of Kansas, Lawrence, Kansas; on leave from the Jagiellonian University, Cracow, Poland. 
10 months old, with open vaginae, were mated to young adult males of the non-inbred ICR Albino stock and checked daily for the presence of vaginal plugs. After a plug had been formed 2 to 4 times without being followed by pregnancy, treatment was initiated. The mice were injected with purified sheep prolactin (NIH-P-s6) dissolved in $0.85 \% \mathrm{NaCl}$, starting on the morning when the plug was found. Seven Snell and seven Ames dwarfs were given 10 i.u. of prolactin daily in two equal doses of 5 i.u. of hormone in $0.05 \mathrm{ml}$ of saline at 09.00 hours $( \pm 1 \mathrm{hr})$ and at 21.00 hours $( \pm 2 \mathrm{hr}$ ). Five Snell and seven Ames dwarfs were given 15 i.u. of prolactin daily in one dose in $0.15 \mathrm{ml}$ of saline at 09.00 hours $( \pm 1 \mathrm{hr})$.

The dose and schedule of injections were determined by a pilot experiment, where the minimal treatment necessary to induce pseudopregnancy in nondwarf adult female mice was found to be 5 i.u. of ovine prolactin given twice daily. The other dose was used to test the necessity of injecting prolactin every $12 \mathrm{hr}$.

If a dwarf mouse failed to become pregnant and continued cycling during 2 to 4 weeks of injections, the treatment was discontinued. In females that became pregnant and delivered, the treatment was continued as long as the young were alive or until the litter was 4 weeks old. Three females, treated with 5 i.u. of prolactin every $12 \mathrm{hr}$, were, during lactation, given 15 i.u. of prolactin every $12 \mathrm{hr}$.

\section{RESULTS}

Of fifty female dwarf mice used in this work, fourteen did not mate, four mated only sporadically and six died soon after mating. The remaining twenty-six mated every 2 to 8 days. None became pregnant without treatment. When prolactin was administered, pregnancy, parturition and lactation occurred in both Snell and Ames dwarfs. The age of treated mice and detailed results of injecting prolactin are given in Table 1 . The number of females that produced living young was chosen as the most meaningful measure of the response to prolactin. The $\chi^{2}$ test for independence was used. Within different treatments there was no significant difference between mutants. Within mutants there was no difference between treatments. When two treatments were pooled there was no difference between mutants. When two mutants were pooled there was a difference between treatments $\left(\chi^{2}=3.91, P=0.02\right.$ to 0.05$)$. The more effective treatment ( 5 i.u. prolactin twice daily) was used to compare the effect of prolactin injections with the results obtained previously with pituitary homografts (Bartke, 1965b). There was no difference in the number of females producing living young, but the litter size was significantly smaller in mice treated with prolactin (Table 2). When the data from grafting non-dwarf pituitary and injecting prolactin twice daily were pooled there was no significant difference in reproduction between Snell and Ames dwarfs.

Of eight Ames dwarf females that became pregnant, all but one ceased to cycle with the start of treatment, while three Snell dwarfs had several more cycles with plug formation before becoming pregnant.

The average weight of seven young that survived to weaning was $10.3 \mathrm{~g}$ 
$(9.5$ to $11.5 \mathrm{~g})$ at the age of 4 weeks. After weaning they soon attained normal size and fertility.

TABLE 1

RESULTS OF PROLACTIN TREATMENT IN FEMALE DWARF MICE

\begin{tabular}{l|c|c|c|c}
\hline & \multicolumn{2}{|c|}{ Dwarf (dw) } & \multicolumn{2}{c}{ Ames dwarf (df) } \\
\cline { 2 - 5 } & $\begin{array}{r}5 \text { i.u. } \\
\text { twice daily }\end{array}$ & $\begin{array}{c}15 \text { i.u. } \\
\text { daily }\end{array}$ & $\begin{array}{c}5 \text { i.u. } \\
\text { twice daily }\end{array}$ & $\begin{array}{c}15 \text { i.u. } \\
\text { daily }\end{array}$ \\
\hline No. of females treated & 7 & 5 & 7 & 7 \\
Age at mating (days) & $160(118-239)$ & $193(152-239)$ & $160(115-228)$ & $170(117-293)$ \\
No. of females that became pregnant & 3 & - & 5 & 3 \\
No. of females that delivered living & 2 & - & 4 & 1 \\
young & 2 & - & 1 & 2 \\
No. of females that failed to deliver & 1 & - & 5 & - \\
No. of females lactating & $1 *$ & - & 2.6 & 2 \\
No. of litters & 2 & - & 3 & 1.5 \\
Mean litter size (living young) & 1.5 & - & & 1 \\
No. of stillborn young & 3 & & & \\
\hline
\end{tabular}

* Hormone dose tripled for the period of lactation.

TABLE 2

COMPARISON OF THE EFFECTS OF PITUITARY GRAFTS AND TREATMENT WITH PROLAGTIN (5 UNITS TWICE DAILY) ON FERTILITY OF FEMALE DWARF MICE (dw/dw AND $\mathrm{df} / \mathrm{df}$ POOLED)

\begin{tabular}{|c|c|c|c|c|}
\hline & Grafts* & Prolactin & $\chi^{2}$ & $P$ \\
\hline No. of females treated & 10 & 14 & & \\
\hline \multirow{3}{*}{$\begin{array}{l}\text { No. of females that became pregnant } \\
\text { No. of females that produced living } \\
\text { young } \\
\text { No. of females that failed to deliver } \\
\text { and died } \\
\text { No. of females lactating }\end{array}$} & 7 & 8 & 0.41 & N.S. \\
\hline & 5 & 6 & $0 \cdot 12$ & N.S. \\
\hline & $\begin{array}{l}1 \\
4\end{array}$ & $\begin{array}{c}2 \\
4 \\
\text { (3 received } \\
\text { triple dose) }\end{array}$ & $0 \cdot 14$ & N.S. \\
\hline No. of litters & 13 & 7 & & \\
\hline Mean litter size (living young) & $5 \cdot 1 \pm 0 \cdot 7$ & $2 \cdot 3 \pm 0 \cdot 3$ & $8 \cdot 65$ & $<0.01$ \\
\hline Stillborn young $(\%)$ & 11 & 27 & 3.69 & N.S. \\
\hline Age at mating (days) & $245(122-425)$ & $160(115-239)$ & & \\
\hline
\end{tabular}

* From Bartke (1965b)

\section{DISCUSSION}

The results confirm the conclusion of previous work that female dwarf mice require prolactin (luteotrophin) to reproduce (Bartke, 1965b). In addition, they indicate that, in female Snell and Ames dwarf mice, prolactin is the only exogenous hormone necessary to ensure pregnancy, parturition and lactation. Consequently, these reproductive functions are possible with the severe deficiency of $\mathrm{GH}$ and thyroxine characteristic for the homozygous dwarf.

It must be pointed out that conclusions from this work may be valid only in the 
stocks of dwarf mice studied, in which the spontaneous onset of the oestrous cycle occurs frequently.

Prolactin content of the pituitary increases sharply after parturition in mouse, rat, guinea-pig and rabbit (Hurst \& Turner, 1942) and in the normal female the initiation of milk production may be due to the increased prolactin secretion in late pregnancy and early lactation (Averill, 1965).

The young of three dwarf females given 5 i.u. of prolactin twice daily died soon after birth, apparently from inanition. One female given this treatment raised one of three young to weaning. When the dose was tripled after parturition (15 i.u. twice daily), lactation was sufficient to raise litters to weaning in two Ames dwarf females, but not in a Snell dwarf female whose young survived only 14 days. Possibly injecting 5 i.u. twice daily could not substitute for the normal rate of prolactin secretion during the first few days after parturition, while a dose three times higher was sufficient.

After receiving pituitary grafts, the number of females that became pregnant and the number of females that delivered living young were no higher than after receiving injections of prolactin twice daily. However, the litter size was much higher in females given grafts (Table 2). Small litter size in females treated with prolactin may have been caused by one of the following factors: (1) changing levels of hormone in the blood as opposed to the presumably constant secretion of prolactin by the pituitary graft; (2) very low contamination of the prolactin preparation with other pituitary hormones as opposed to small but significant amounts of $\mathrm{GH}$ and TSH released from the pituitary grafts (evidence from work on the rat: Hertz, 1959; Meites \& Kragt, 1964); (3) possible partial species specificity of sheep prolactin; and (4) using males from a different stock. The relevance of (1) is further indicated by the inferior reproductive performance of females given prolactin once daily in which the fluctuation of the hormone blood level was still higher, while the influence of (4) seems very unlikely since the ICR Albino stock is noted for high fertility and large litter size (average thirteen).

\section{ACKNOWLEDGMENTS}

This work was supported by PHS Grant GM-10112 and American Cancer Society Grant IN-49. Purified prolactin was generously provided by the Endocrinology Study Section, National Institutes of Health. The author wishes to express sincere thanks to Dr T. R. Talbot, Jr., Dr J. Schultz and Dr G. L. Wolff for providing space and facilities for this work.

\section{REFERENCES}

Averict, R. L. (1965) Restoration of lactation in rats with hypothalamic lesions which inhibit lactation. 7. Endocr. 31, 191.

BARTKE, A. (1965a) Absence of prolactin activity in pituitaries of dwarf mice. (Abstract). Genetics, 52, 426. Bartke, A. (1965b) Influence of luteotrophin on fertility of dwarf mice. F. Reprod. Fert. 10, 93.

Hertz, R. (1959) Growth in the hypophysectomized rat sustained by pituitary grafts. Endocrinology, $65,926$.

Hurst, V. \& TURNER, C. W. (1942) Lactogenic hormone content of anterior pituitary gland of albino mouse as compared to other species. Endocrinology, 31, 334 .

MeItes, J. \& KRAGT, C. L. (1964) Effects of a pituitary homotransplant and thyroxine on body and mammary growth in immature hypophysectomized rats. Endocrinology, 75, 565. 